\title{
Agricultural drought monitoring in Tamil Nadu in India using Satellite-based multi vegetation indices
}

Kumaraperumal. $\mathbf{R}^{*}$

Department of Remote Sensing and GIS, Tamil Nadu Agricultural University, Coimbatore641003 (Tamil Nadu), India

\section{Pazhanivelan. S.}

Department of Remote Sensing and GIS, Tamil Nadu Agricultural University, Coimbatore641003 (Tamil Nadu), India

\section{Ragunath. K.P.}

Department of Remote Sensing and GIS, Tamil Nadu Agricultural University, Coimbatore641003 (Tamil Nadu), India

\section{Balaji Kannan}

Water Technology Centre, Tamil Nadu Agricultural University, 641003 (Tamil Nadu), India

Prajesh. P.J.

Department of Remote Sensing and GIS, Tamil Nadu Agricultural University, Coimbatore641003 (Tamil Nadu), India

Mugilan. G.R.

Department of Remote Sensing and GIS, Tamil Nadu Agricultural University, Coimbatore641003 (Tamil Nadu), India

*Corresponding author. Email: kumaraperumal.r@gmail.com

\section{Article Info}

https://doi.org/10.31018/

jans.v13i2.2585

Received: February 23, 2021

Revised: April 26, 2021

Accepted: May 2, 2021

\section{How to Cite}

Kumaraperumal, R. et al. (2021). Agricultural drought monitoring in Tamil Nadu in India using Satellite-based multi vegetation indices. Journal of Applied and Natural Science, 13(2), 414 - 423. https://doi.org/10.31018/jans.v13i2.2585

\begin{abstract}
Drought being an insidious hazard, is considered to have one of the most complex phenomenons. The proposed study identifies remote sensing-based indices that could act as a proxy indicator in monitoring agricultural drought over Tamil Nadu's region India. The satellite data products were downloaded from 2000 to 2013 from MODIS, GLDAS - NOAH, and TRMM. The intensity of agricultural drought was studied using indices viz., NDVI, NDWI, NMDI, and NDDI. The satellite-derived spectral indices include raw, scaled, and combined indices. Comparing satellite-derived indices with in-situ rainfall data and 1-month SPI data was performed to identify exceptional drought to no drought conditions for September month. The additive combination of NDDI showed a positive correlation of 0.25 with rainfall and 0.23 with SPI, while the scaled NDDI and raw NDDI were negatively correlated with rainfall and SPI. Similar cases were noticed with raw LST and raw NMDI. Indices viz., LST, NDVI, and NDWI performed well; however, it was clear that NDWI performed better than NDVI while LST was crucial in deciding NDVI coverage over the study area. These results showed that no single index could be put forward to detect agricultural drought accurately, however, an additive combination of indices could be a successful proxy to vegetation stress identification.
\end{abstract}

Keywords: Agricultural Drought, Land Use, MODIS, SPI, Vegetation Indices

\section{INTRODUCTION}

The concept of remote sensing technology in agricultural drought detection and monitoring through stress detection and ecological changes has provided continuous valuable insights (AghaKouchak et al., 2015). Since drought is an essential aspect of climate variability and climate change, drought indices such as the PDSI - Palmer Drought Severity Index (Palmer, 1965) or SPI - Standard Precipitation Index (McKee, 1995; McKee et al., 1993) were calculated based on rainfall, evapo-transpiration, and in-situ ground weather station. However, scattered distribution of these stations proves to be a barrier in providing continuous data.

Studies have shown that agricultural drought assessment can be reliably measured using space-driven data to fill the void left by the limited sampling gauges and in -situ methods that lack spatial variations (Rhee et al., 
2010). Depending on the geospatial data, several remote sensing-based vegetation indices were adopted to identify drought severity (Rhee et al., 2010). Among these Normalised Difference Vegetation Index (NDVI) (Rouse et al., 1974), which uses normalised reflectance between Near-Infrared (NIR) and red channels of the electromagnetic spectrum, was widely used for monitoring agricultural drought. With NDVI measuring changes in chlorophyll content of vegetation canopy, a significant limitation exists that is the apparent time lag period between NDVI response towards rainfall deficit (Di et al., 1994). Given the importance of water in crop canopy, Gao (1996) proposed Normalized Difference Water Index (NDWI), which uses SWIR (Short Wave Infrared) in combination with NIR band to remove the variations induced by the internal leaf structure and dry matter content, hence improving accuracy in retrieving vegetation water content (Ceccato et al., 2001). With the SWIR band's inclusion, NDWI has been considered a sensitive indicator of drought conditions ( $\mathrm{Gu}$ et al., 2007). The past studies showed the sensitivity of NDVI and NDWI for vegetation stress detection and drought monitoring (Farrar et al., 1994; Gu et al., 2007), and hence a new methodology was proposed by combining vegetation and water-related index (Gu et al., 2007). The combined information based on NDVI and NDWI values suggested a more sensitive summer drought detection index called the Normalised Difference Drought Index (NDDI). Wang and Qu, (2007) proposed monitoring vegetation stress along with moisture availability on highly vegetated areas and termed as Normalised Multi-Band Drought Index (NMDI), which combines two channels of SWIR band (1640 $\mu \mathrm{m}$ and $2130 \mu \mathrm{m})$ along with Near Infrared (NIR) band of MODIS (Moderate Resolution Imaging Spectroradiometer). NMDI was developed based on the fact that SWIR is more responsive to soil and vegetation moisture, further improving the index's sensitivity for drought severity monitoring.

Drought frequencies have been distinctive in India's many regions (Mishra and Liu, 2014). Studies by Gupta et al. (2020) and Ge et al. (2016) highlighted that the frequencies of severe drought with an extended return period is projected to increase and is expected to be highest for the period between 2071-2100. Similarly, Aadhar and Misra (2018) reported the role of increased eveapotranspiration due to anthropogenic activities to be one of the significant factors in the increase of drought frequencies in India. A typical paradox example to highlight this is the increasing regional drought frequencies and wavering drought severity in Tamil Na$\mathrm{du}$, which is a North-East Monsoon rainfall dependent state (GOI, 2018). At present, with the availability and ability of land surface parameters at high temporal resolution obtained using TERRA satellite based MODIS sensor, provides an insight on crop stress response.
The study here examines Land Surface Temperature (LST) performance, Tropical Rainfall Measuring Mission (TRMM) and vegetation-based indices derived from MODIS against rainfall variables with an objective to i) Identify a suitable index for agricultural drought monitoring in Tamil Nadu based on correlation analysis between remote sensing based vegetation indices and in-situ meteorological data, ii) Demonstrate the robustness by comparing the vegetation indices map with aggregated monthly SPI map of September.

\section{MATERIALS AND METHODS}

\section{Study area}

The region of Tamil Nadu (Fig.1) stretches between $8.5^{\circ} \mathrm{N}$ and $13.35^{\circ} \mathrm{N}$ latitude and $78.35^{\circ} \mathrm{E}$ and $80.20^{\circ} \mathrm{E}$ Longitude. Overall, the region's agricultural area accounts for $13630.053 \mathrm{sq}$. km of Rabi cropland and $5232.520 \mathrm{sq}$. km. of Kharif cropland. Bi- monsoonal patterns dominated rainfall exists in the sub-agroclimatic zones of Tamil Nadu (DES, 2011). The state misses most of the rainfall during the southwest monsoon, hence making the region dependent on northeast monsoon rainfall.

\section{Datasets}

The following remote sensing datasets from various sensors and in-situ ground datasets were downloaded for 2000 to 2013 (Julian days from 145 to 273) each year with a total of $476(238 * 2$ tiles) satellite data from each sensor.

\section{MODIS land data product}

TERRA derived MODIS based surface reflectance and LST (Land Surface Temperature) data of h25v7 and h25v8, a title corresponding to the Tamil Nadu area, was obtained from the Land Processes Distribute Active Archive Centre (LP DAAC) of NASA (http:// search.earthdata.nasa.gov). An 8-day composite Land Surface Temperature (LST) product (MOD11A2) with a spatial resolution of $1 \mathrm{~km}$ was downloaded to extract daytime land surface temperature and emissivity for assessing vegetation condition.

\section{GLDAS- NOAH land surface data}

In considering the cloud contamination in MODIS, the Global Land Data Assimilation System (GLDAS)-NOAH Land Surface Model (L4) three hours data downloaded at $0.25 \times 0.25$-degree spatial resolution from the NASA Goddard Earth Science (GES) data and Information Service Centre (DISC) https://disc.gsfc.nasa.gov/.

\section{Rainfall data}

Gridded rainfall data of daily precipitation was extracted from Tropical Rainfall Measuring Mission product (TRMM 3B42) at a level of $0.25^{\circ}$ spatial resolution for a 


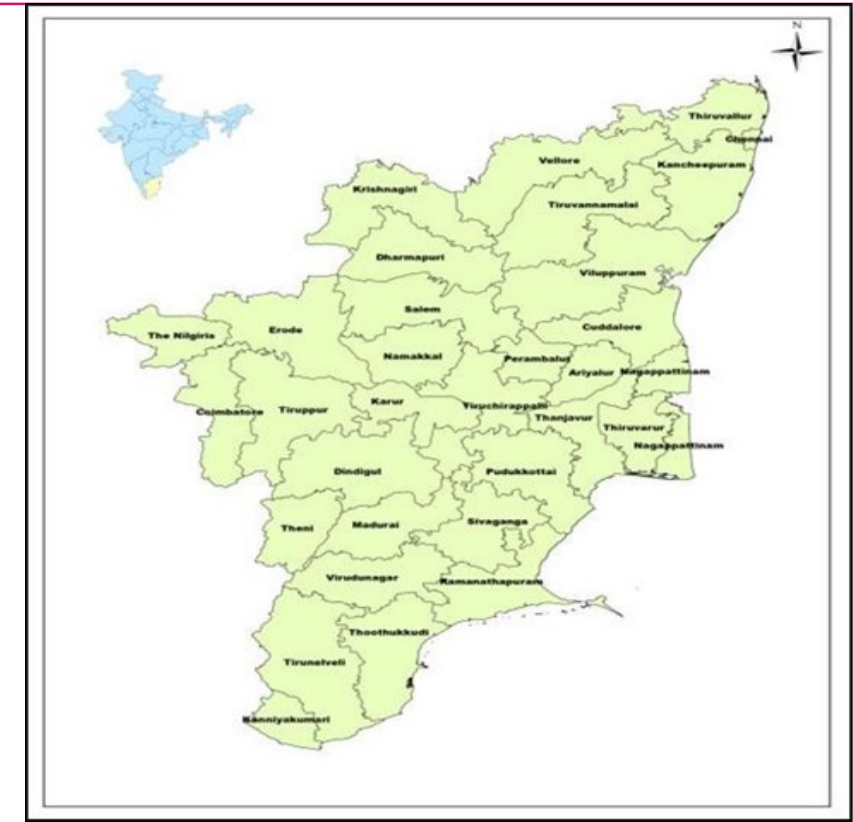

Fig. 1. Study area map with land use and land cover map.

global extent http://mirador.gsfc.nasa.gov for calculation of monthly rainfall.

\section{In-situ precipitation data}

The in-situ rainfall data was collected from the Tamil Nadu Public Works Department (PWD) from 1970 to 2013 and later processed monthly to calculate the Standard Precipitation Index. SPI was derived since it was a spatially invariant indicator of drought, and its quantitative nature used to detect anomalies over different time scales.

\section{Pre-processing of satellite data}

The pre-processing of land data product viz., LST and MODIS data is performed using the MODIS Reprojection Tool (MRT). Tiles of h25v7 and h25v8 were mosaicked, followed by projection from Sinusoidal to Universal Transverse Mercator, and finally subsetting the satellite data for the rectangular extent of Tamil Nadu.

TRMM available in .netCDF format was processed using Model Builder and Python Scripting in ArcGIS. The TRMM reprojection model developed using the Model Builder in ArcGIS to automatically correct the projection parameters and subset each satellite data for the rectangular extent of Tamil Nadu.

Because of the difference in temporal resolution and time-lag between MODIS and TRMM, TRMM data combined for eight days to match the Julian days (8day composite) of MODIS data. A python script was used for automating the process using Arcpy module. Since optical imagery was subjected to image distortion due to clouds, particularly during the cropping season of June to September, LST's cloud pixels replaced with GLDAS NOAH LST. Fig. 2 depicts the pre-processing of satellite datasets.

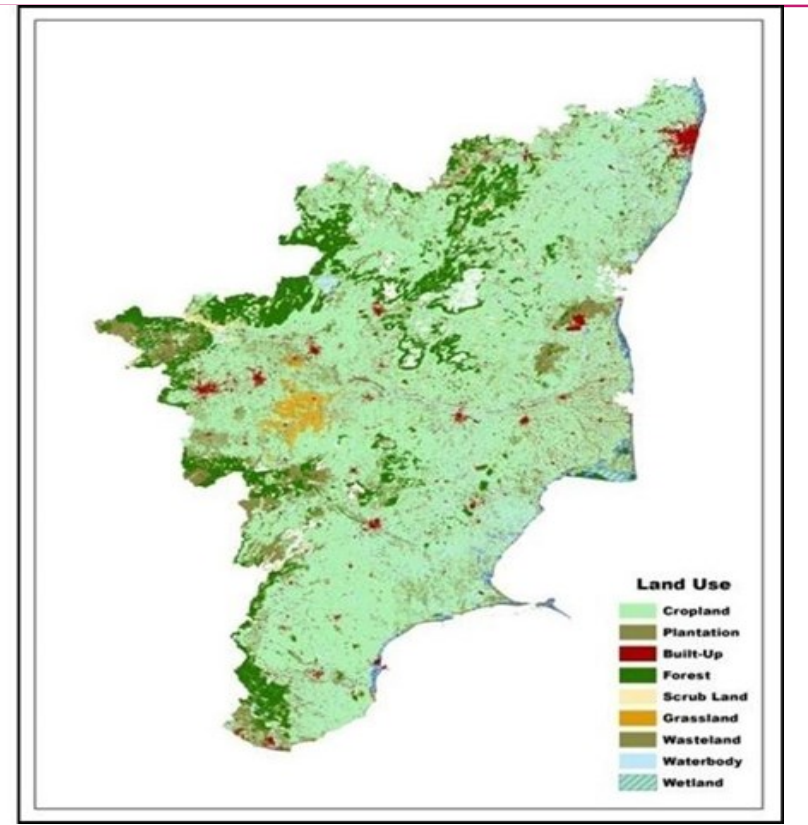

Calculation of vegetation indices

Based on Rhee et al. (2010) approach for drought detection in arid and semiarid regions, this study also utilised vegetation indices viz., NDVI, NDWI, NMDI and NDDI, temperature index viz., LST and weather component viz., TRMM. These were extracted and categorised as raw variables, scaled variables, and combined variables (Table 1). Apart from removing the mentioned indices and components, SWIR channels (band 5, band 6 , and band 7) were tested separately for NDDI and NDWI due to different SWIR band sensitivity in sensing vegetation moisture content.

To minimise the effect of inter-annual variations of vegetation index values resulting from weather fluctuation and ecosystem components, scaling of indices was done (Kogan, 1995). Vegetation indices, LST, and the TRMM values were scaled from 0 to 1 range for each pixel, wherein 0 meant the driest condition and 1 represents the wettest condition. Additive combinations of variables, including vegetation components, temperature components, and precipitation components, were also tested based on three weights combinations and compared with 1-month SPI and rainfall to understand the performance. The purpose of following this approach was to try the nature of indices in detecting agricultural drought over the climatic and land covers of Tamil Nadu. Fig. 3 explains the detailed methodology.

\section{Processing of in-situ rainfall}

For rainfall data processing, station point values were created in the ArcGIS using the respective longitude and latitude and rainfall values. The monthly rainfall data are spatially interpolated based on the Inverse Distance Weighted Average Algorithm to produce a rainfall surface at $500 \mathrm{~m}$ spatial resolution. 
Table 1. Formula for remote sensing derived indices extraction using various wavelength bands ( $\rho$ represented the spectral reflectance).

\begin{tabular}{|c|c|c|c|}
\hline \multicolumn{2}{|c|}{ Vegetation Indices } & Formula & Reference \\
\hline \multicolumn{2}{|c|}{$\begin{array}{l}\text { Raw Indices } \\
\text { NDVI } \\
\text { Normalized Difference Vegetation } \\
\text { Index }\end{array}$} & ( $\rho$ band $2-\rho$ band 3$) /(\rho$ band $2+\rho$ band 3$)$ & $\begin{array}{l}\text { (Rouse et al., } \\
\text { 1974) }\end{array}$ \\
\hline NDWI & $\begin{array}{l}\text { NDWI5 } \\
\text { SWIR Band } 5 \text { (1230- } \\
1250 \mathrm{~nm} \\
\text { NDWI6 } \\
\text { SWIR Band } 6 \text { (1628- } \\
1652 \mathrm{~nm}) \\
\text { NDWI7 } \\
\text { SWIR Band } 7 \text { (2105- } \\
2155 \mathrm{~nm})\end{array}$ & ( $\rho$ band $2-\rho$ band 7$) /(\rho$ band $2+\rho$ band 7$)$ & (Gao, 1996) \\
\hline NDDI & $\begin{array}{l}\text { NDDI5 (SWIR Band 5) } \\
\text { NDDI6 (SWIR Band 5) } \\
\text { NDDI7 (SWIR Band 5) } \\
\end{array}$ & $\begin{array}{l}\text { (NDVI-NDWI5)/(NDVI+NDWI5) } \\
\text { (NDVI-NDWI6)/(NDVI+NDWI6) } \\
(\mathrm{NDVI-NDWI7)/(NDVI+NDWI7)} \\
\end{array}$ & (Gu et al., \\
\hline $\begin{array}{l}\text { NMDI } \\
\text { Normali } \\
\text { dex }\end{array}$ & ed Multiband Drought In- & $\begin{array}{l}(\rho \text { band } 2-(\rho \text { band } 6-\rho \text { band } 7)) /(\rho \text { band } 2+(\rho \text { band } 6-\rho \\
\text { band } 7))\end{array}$ & $\begin{array}{l}\text { (Wang and } \\
\text { Qu, 2007) }\end{array}$ \\
\hline \multicolumn{4}{|c|}{ Scaled Indices } \\
\hline Scaled I & & (LSTmax-LST)/(LSTmax-LSTmin) & \multirow{10}{*}{$\begin{array}{l}\text { (Kogan, 1995; } \\
\text { Rhee et al., } \\
\text { 2010) }\end{array}$} \\
\hline Scaled & RMM & (TRMM-TRMMmin) /(TRMMmax-TRMMmin) & \\
\hline $\begin{array}{l}\text { Scaled I } \\
\text { tion Inde }\end{array}$ & $\begin{array}{l}\text { DVI (= Vegetation Condi- } \\
\text { ) }\end{array}$ & (NDVI-NDVImin) /(NDVImax-NDVImin) & \\
\hline Scaled I & 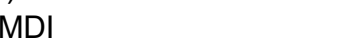 & (NMDImax-NMDI)/(NMDImax-NMDImin) & \\
\hline Scaled I & DWI5 & (NDWI5-NDWI5min) /(NDWI5max-NDWI5min) & \\
\hline Scaled I & DWI6 & (NDWI6-NDWI6min) /(NDWI6max-NDWI6min) & \\
\hline Scaled I & DWI7 & (NDWI7-NDWI7min) /(NDWI7max-NDWI7min) & \\
\hline Scaled I & DDI5 & (NDDI5max-NDDI5)/(NDDI5max-NDDI5min) & \\
\hline Scaled I & DDI6 & (NDDI6max-NDDI6)/(NDDI6max-NDDI6min) & \\
\hline Scaled I & DDI7 & (NDDI7max-NDDI7)/(NDDI7max-NDDI7min) & \\
\hline \multicolumn{4}{|c|}{ Combined Indices } \\
\hline \multicolumn{2}{|c|}{ Vegetation Health Index (VHI) } & $(1 / 2) \times$ scaled LST+(1/2)×scaled NDVI & (Kogan, 1995) \\
\hline Combin & d index1 (Cl1) & 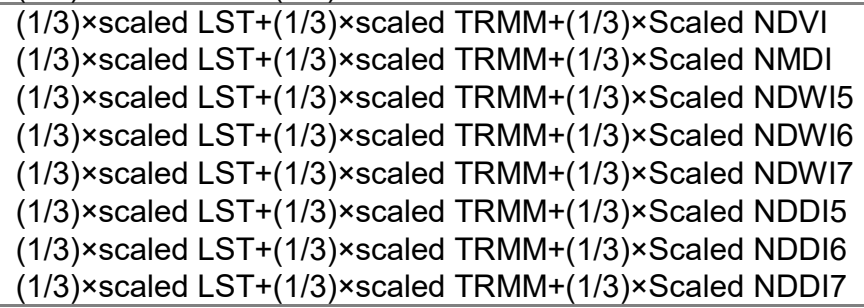 & $\begin{array}{l}\text { (Rhee et al., } \\
\text { 2010) }\end{array}$ \\
\hline Combin & d index2 (Cl2) & 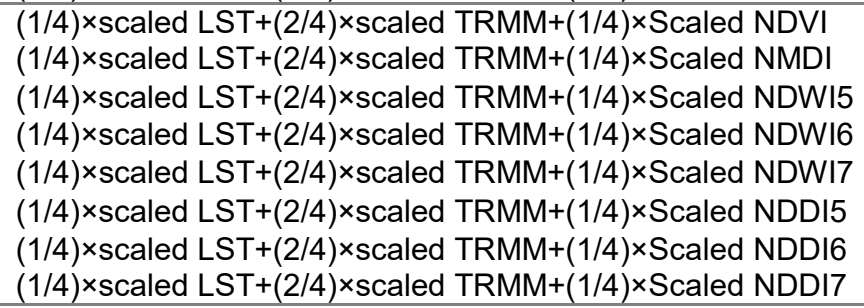 & $\begin{array}{l}\text { (Rhee et al., } \\
\text { 2010) }\end{array}$ \\
\hline Combin & index $3(\mathrm{Cl} 3)$ & 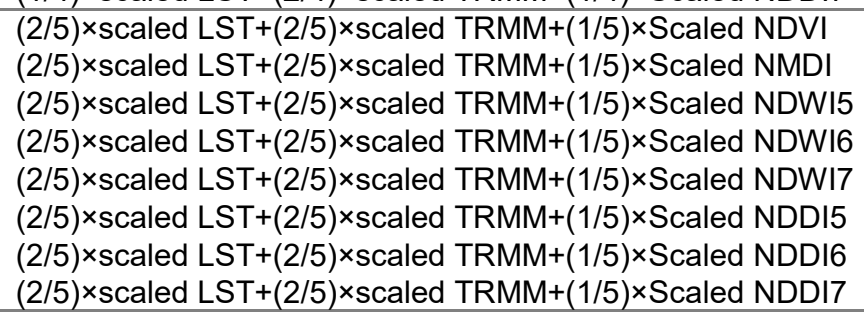 & $\begin{array}{l}\text { (Rhee et al., } \\
\text { 2010) }\end{array}$ \\
\hline
\end{tabular}




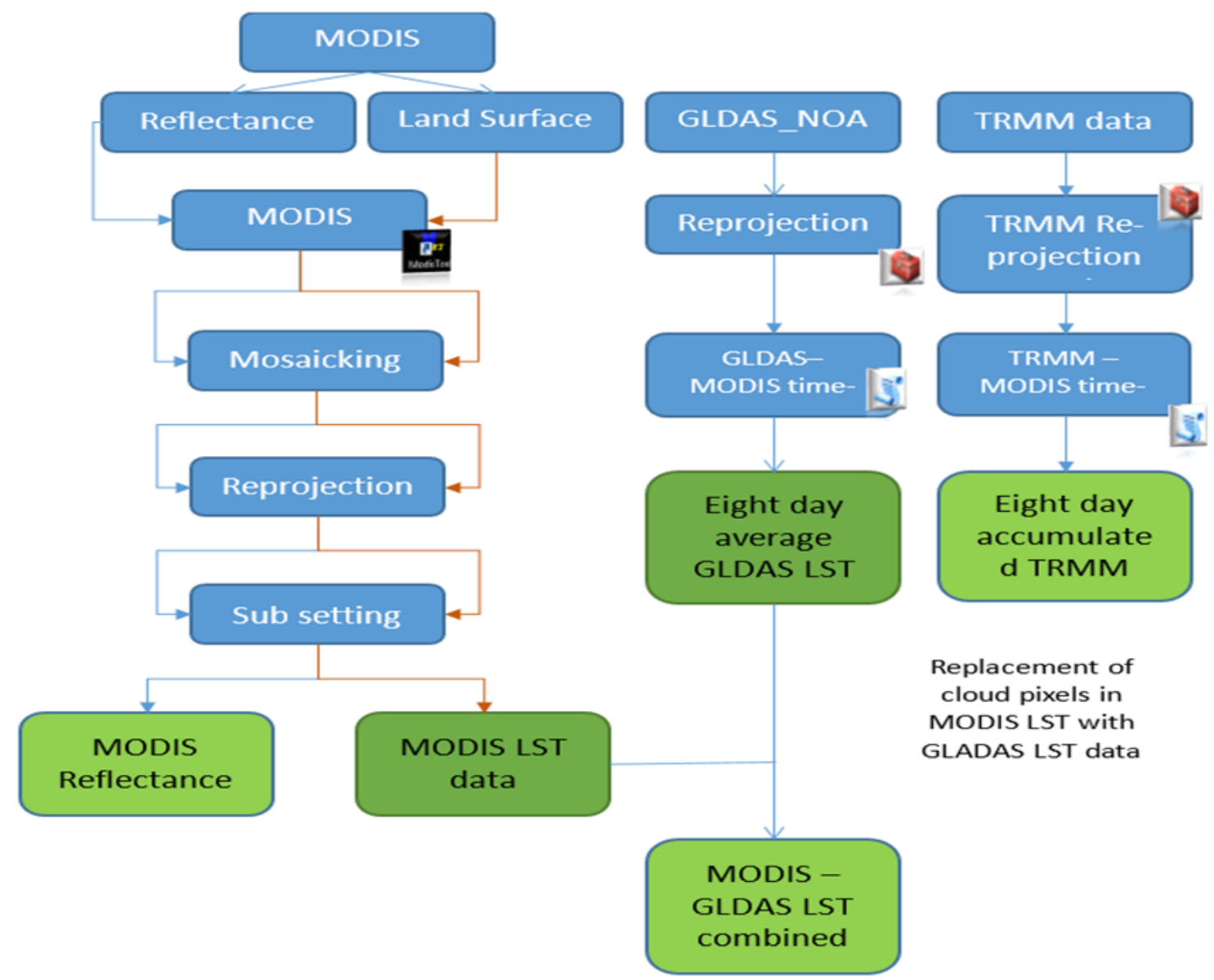

Fig. 2. Pre-processing of satellite data.

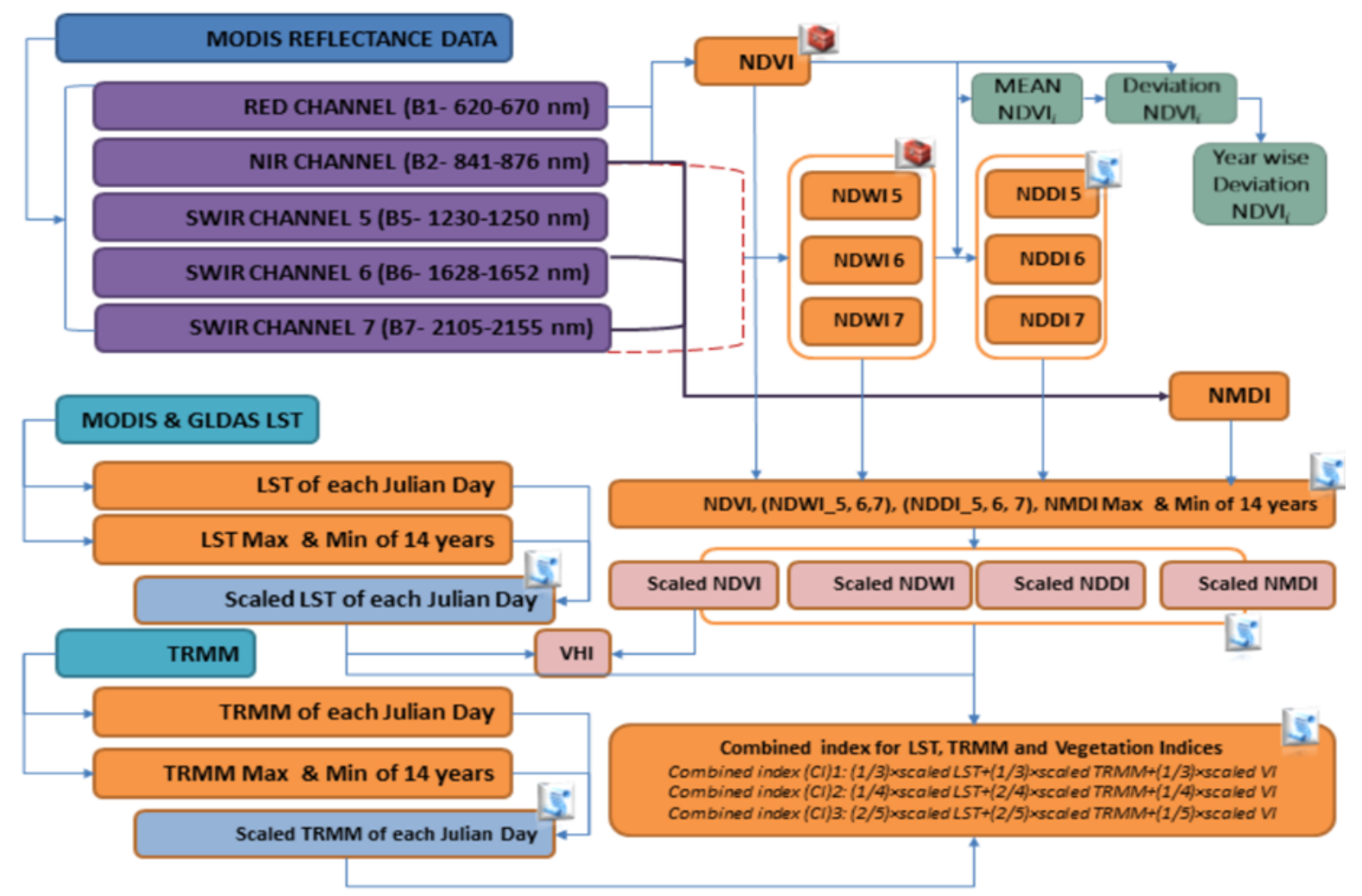

Fig. 3. Methodology adopted for deriving drought indices using remote sensing. 
SPI has been used to assess the impact of rainfall deficiency and quantify the precipitation deficit in the monsoon periods from 1970 to 2013 . The standardised precipitation index calculated using equation (1).

$\mathrm{SPI}=\left(\mathrm{X}_{\mathrm{ij}}-\mathrm{X}_{\mathrm{im}}\right) / \sigma$

Where,

$X_{i j}$ denotes seasonal precipitation at $i^{\text {th }}$ rain gauge station, and $\mathrm{j}^{\text {th }}, \mathrm{X}_{\mathrm{im}}$ observation denotes long term seasonal mean. $\sigma$ is its standard deviation. The SPI maps were generated using the SPIRITS software for all the years.

Correlation analysis of remote sensing derived indices and meteorological variables

The climatic factors' behaviour is one of the critical aspects of drought monitoring that provides a better understanding of vegetation development and degradation. Remote sensing index values were subjected to Pearson correlation analysis against 1-month SPI and rainfall over 2000 to 2013 growing season. The remotely sensed index and SPI / Rainfall data are correlated spatially on a pixel by pixel basis. The coefficient range depicted information on the strength/weakness of vegetation growth and rainfall influence.

\section{RESULTS AND DISCUSSION}

Raw vegetation indices against painfall and precipitation

Values of the correlation coefficient between remote sensing variable with 1-month SPI and rainfall are provided in Table 2, while maps in Fig. 4 shows raw indices comparison with SPI that ranges from -1 to 1 . Value from 0 to 1 shows the increasing trend in vegetation greenness and water content, while sparse to no vegetation goes from -1 to 0 . Irrespective of the index used, rainfall shows a slightly higher positive correlation than SPI for the entire index except for LST and NDDI. Land

Table 2. Correlation coefficient of raw remote sensing variable with in-situ variables.

\begin{tabular}{llll}
\hline Type & Remote Sensing Index & Rainfall & SPI \\
\hline Raw & LST & -0.24 & -0.2 \\
Raw & TRMM & 0.58 & 0.43 \\
Raw & NDVI & 0.26 & 0.12 \\
Raw & NMDI & -0.08 & -0.11 \\
Raw & NDWI5 & 0.27 & 0.15 \\
Raw & NDWI6 & 0.35 & 0.19 \\
Raw & NDWI7 & 0.34 & 0.2 \\
Raw & NDDI5 & -0.16 & -0.1 \\
Raw & NDDI6 & -0.27 & -0.16 \\
Raw & NDDI7 & -0.24 & -0.16 \\
\hline
\end{tabular}

Surface Temperature (LST) has a negative correlation of -0.24 (rainfall) and -0.20 (SPI), which indicated that LST alone could not be used to analyse the agricultural drought situation. The rainfall estimate derived from TRMM recorded higher correlation values of 0.58 and 0.43 with in-situ rainfall and SPI variables. In the absence of in-situ rainfall data, TRMM data can be used alone or in combination with the available in-situ rainfall data for analysing the drought scenario (Rousta et al., 2020).

Studies by Di et al. (1994); Farrar et al. (1994); Wang et al. (2001) showed a significant relationship between NDVI, precipitation, and moisture; however, this study on NDWI against rainfall and SPI showed higher correlation values compared to crop greenness based indices, which qualifies on the inclusion of shortwave infrared channel reflectance (SWIR) in NDWI that are less affected by atmospheric scattering (Aghakouchak et al., 2015). Among the SWIR channels of the MODIS sensor, SWIR 6 and SWIR 7 showed a better correlation than the SWIR channel five, which is also in line with similar results drawn by Rhee et al., 2010 for arid and semiarid region drought detection.

The newly developed NMDI and NDDI indices negatively correlate with in-situ variables. The correlation results of NDDI 5 (-0.16 and -0.1$)$, NDDI 6 (-0.27 and $0.16)$, and NDDI 7 ( -0.24 and -0.16$)$ with rainfall and SPI, respectively, clearly indicates that combining the information using the difference between two liquid water absorption cannot be utilised as a reliable indicator for summer drought analysis (Wang and Qu, 2007) when there is the presence of variability in regional soil moisture and vegetation moisture (Rhee et al., 2010).

\section{Scaled vegetation indices against rainfall and precipitation}

Higher correlation values were noticed for scaled indices compared to raw indices when tested against in-

Table 3. Correlation coefficient values of scaled remote sensing indices with in-situ variables.

\begin{tabular}{llll}
\hline Type & Remote Sensing Index & Rainfall & SPI \\
\hline Scaled & Scaled LST & 0.19 & 0.23 \\
Scaled & Scaled TRMM & 0.47 & 0.45 \\
Scaled & ScaledNDVI & 0.15 & 0.16 \\
Scaled & ScaledNMDI & 0.10 & 0.11 \\
Scaled & ScaledNDWI5 & 0.20 & 0.19 \\
Scaled & ScaledNDWI6 & 0.26 & 0.24 \\
Scaled & ScaledNDWI7 & 0.26 & 0.25 \\
Scaled & ScaledNDDI5 & -0.19 & -0.22 \\
Scaled & ScaledNDDI6 & -0.19 & -0.23 \\
Scaled & ScaledNDDI7 & -0.19 & -0.22 \\
\hline
\end{tabular}


Table 4. Correlation coefficient values of combined indices with in-situ variables.

\begin{tabular}{|c|c|c|c|}
\hline Type & Remote Sensing Index & Rainfall & SPI \\
\hline $\mathrm{VHI}$ & LST, NDVI & 0.26 & 0.30 \\
\hline $\mathrm{Cl} 1$ & Scaled LST, Scaled TRMM, Scaled NDVI & 0.43 & 0.46 \\
\hline $\mathrm{Cl} 1$ & Scaled LST, Scaled TRMM, Scaled NMDI & 0.39 & 0.42 \\
\hline $\mathrm{Cl} 1$ & Scaled LST, Scaled TRMM, Scaled NDWI5 & 0.37 & 0.37 \\
\hline $\mathrm{Cl} 1$ & Scaled LST, Scaled TRMM, Scaled NDWI6 & 0.44 & 0.45 \\
\hline $\mathrm{Cl} 1$ & Scaled LST, Scaled TRMM, Scaled NDWI7 & 0.45 & 0.46 \\
\hline $\mathrm{Cl} 1$ & Scaled LST, Scaled TRMM, Scaled NDDI5 & 0.24 & 0.23 \\
\hline $\mathrm{Cl} 1$ & Scaled LST, Scaled TRMM, Scaled NDDI6 & 0.25 & 0.23 \\
\hline $\mathrm{Cl} 1$ & Scaled LST, Scaled TRMM, Scaled NDDI7 & 0.26 & 0.26 \\
\hline $\mathrm{Cl} 2$ & Scaled LST, Scaled TRMM, Scaled NDVI & 0.48 & 0.49 \\
\hline $\mathrm{Cl} 2$ & Scaled LST, Scaled TRMM, Scaled NMDI & 0.45 & 0.46 \\
\hline $\mathrm{Cl} 2$ & Scaled LST, Scaled TRMM, Scaled NDWI5 & 0.42 & 0.41 \\
\hline $\mathrm{Cl} 2$ & Scaled LST, Scaled TRMM, Scaled NDWI6 & 0.49 & 0.49 \\
\hline $\mathrm{Cl} 2$ & Scaled LST, Scaled TRMM, Scaled NDWI7 & 0.49 & 0.49 \\
\hline $\mathrm{Cl} 2$ & Scaled LST, Scaled TRMM, Scaled NDDI5 & 0.35 & 0.34 \\
\hline $\mathrm{Cl} 2$ & Scaled LST, Scaled TRMM, Scaled NDDI6 & 0.35 & 0.34 \\
\hline $\mathrm{Cl} 2$ & Scaled LST, Scaled TRMM, Scaled NDDI7 & 0.36 & 0.36 \\
\hline $\mathrm{Cl} 3$ & Scaled LST, Scaled TRMM, Scaled NDVI & 0.44 & 0.47 \\
\hline $\mathrm{Cl} 3$ & Scaled LST, Scaled TRMM, Scaled NMDI & 0.42 & 0.44 \\
\hline $\mathrm{Cl} 3$ & Scaled LST, Scaled TRMM, Scaled NDWI5 & 0.38 & 0.38 \\
\hline $\mathrm{Cl} 3$ & Scaled LST, Scaled TRMM, Scaled NDWI6 & 0.45 & 0.46 \\
\hline $\mathrm{Cl} 3$ & Scaled LST, Scaled TRMM, Scaled NDWI7 & 0.45 & 0.47 \\
\hline
\end{tabular}

situ variables. Table 3 depicts the correlation coefficient values for scaled indices with rainfall and SPI. Map in Fig. 5 shows a comparison of scaled variables with SPI for September 2013, which indicates the presence of no drought $(>0.5-1)$ to exceptional drought $(0.0-0.1)$ situation.

The scaled TRMM index correlates with rainfall (0.47) and SPI (0.45) compared to other indices based on the results. The raw LST and NMDI and scaled LST and NMDI also positively correlated with rainfall and SPI, suggesting that inter-annual soil and vegetation variability are essential in effective drought monitoring. Among the scaled remote sensing variables, scaled LST, scaled TRMM, scaled NDVI, scaled NDWI 6, and scaled NDWI 7 correlates high within-situ variables relatively. This finding, which is similar to raw index

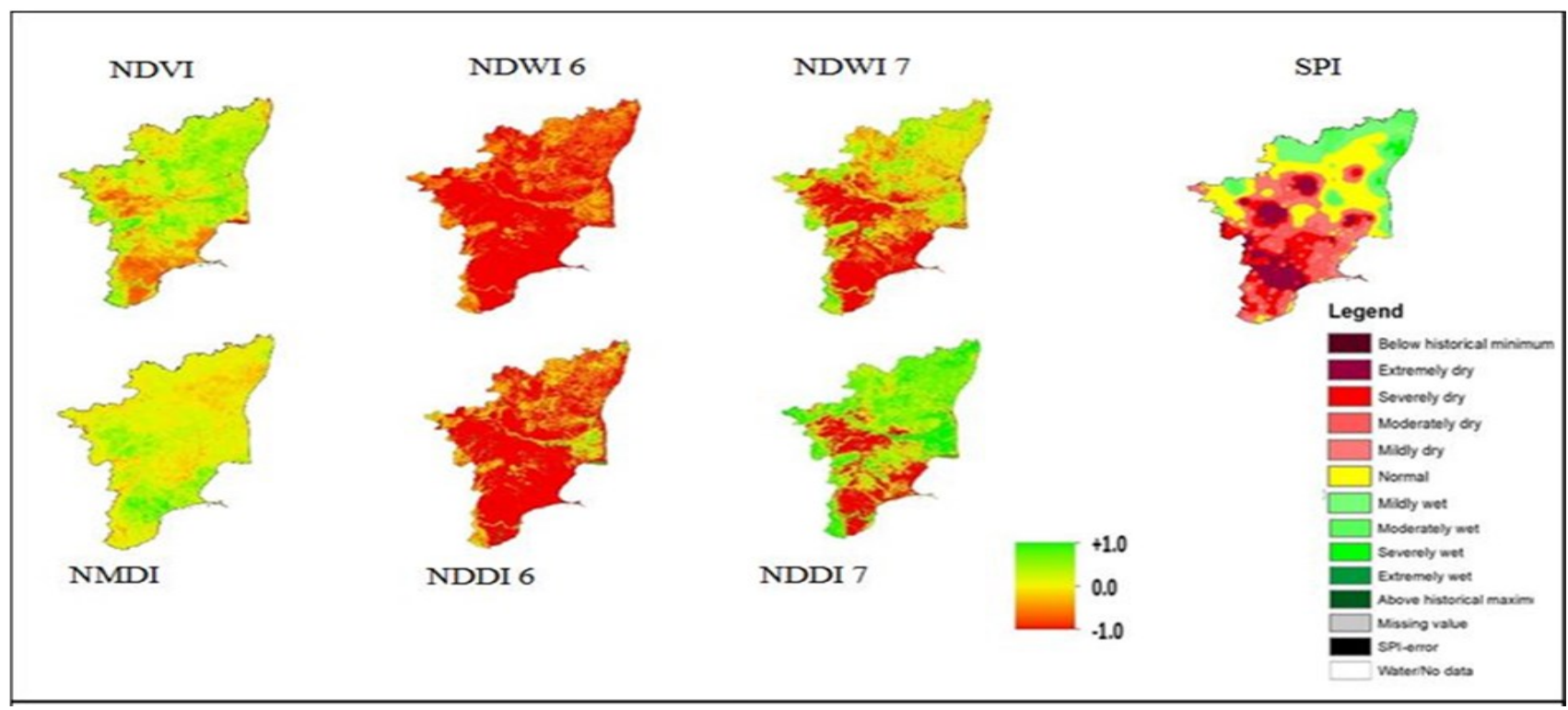

Fig. 4. Comparison of SPI with remote sensing based raw indices for September 2013. 


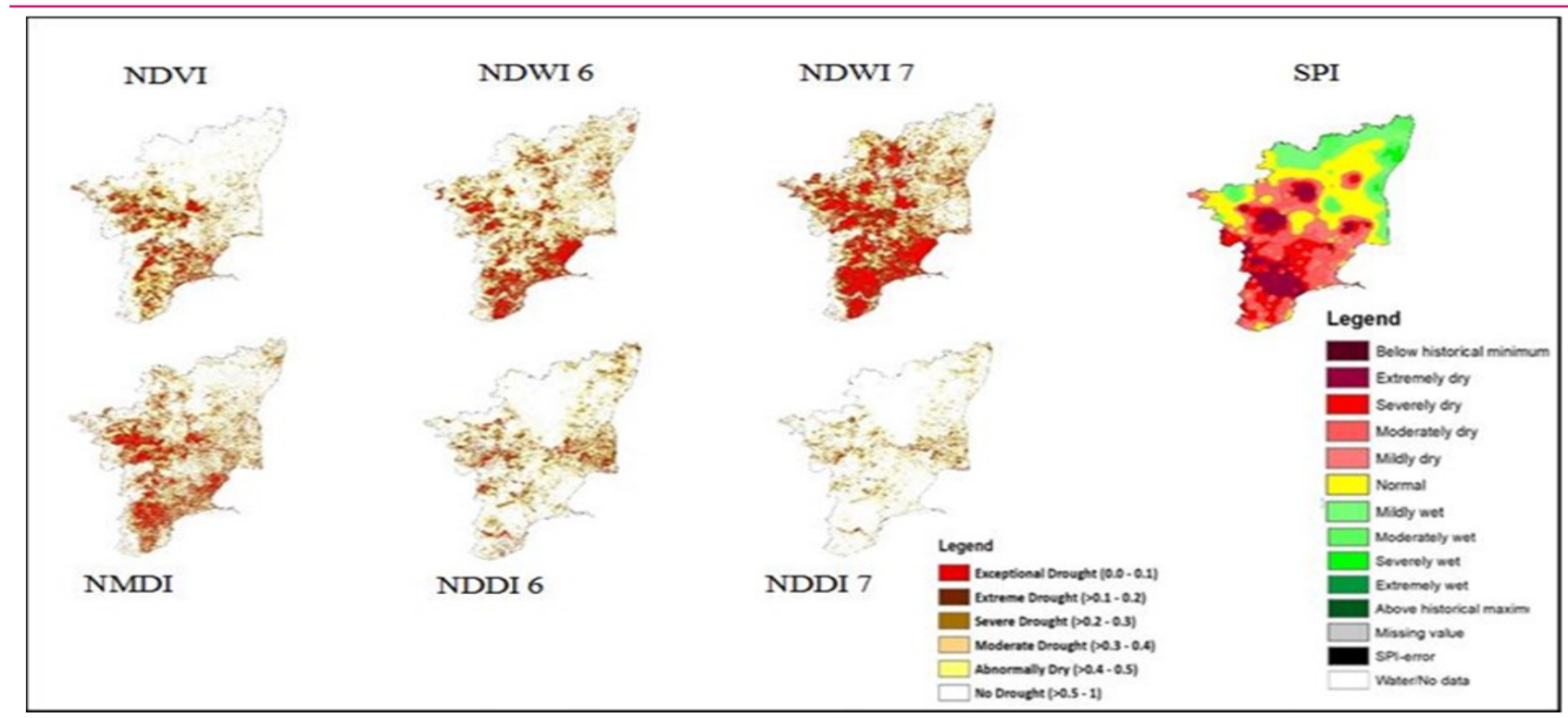

Fig. 5. Comparison of SPI with remote sensing based scaled indices for September 2013.

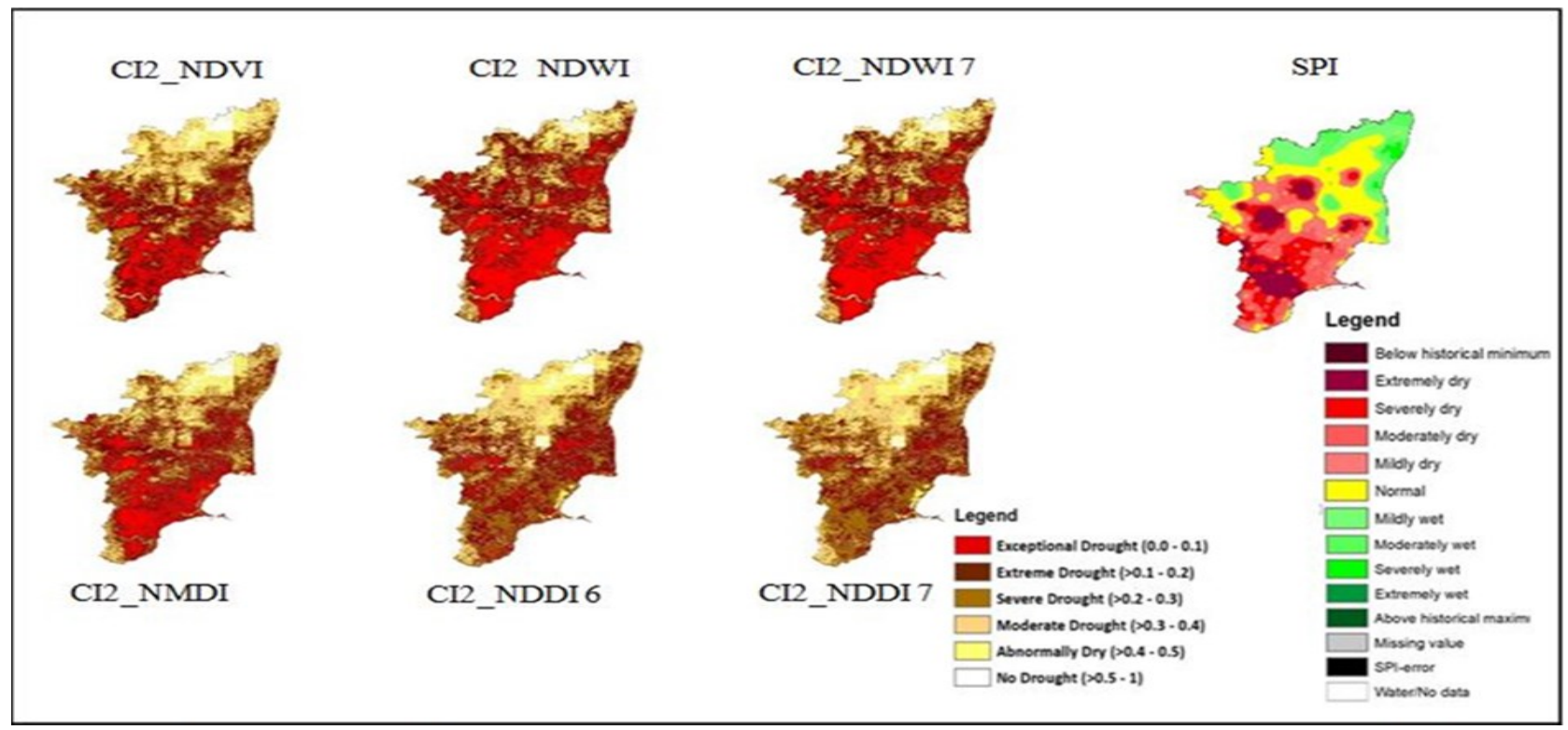

Fig. 6. Comparison of SPI drought assessment maps with combined indices 2 for September 2013.

finding, proves that drought detection through precipitation variation can contribute to vegetation variation and land surface temperature. Such a conclusion is consistent with Ji and Peters, 2003.

NDVI still performed significantly well over NMDI, NDWI5, and NDDI. Indices involve more information on biophysical response to drought, including change of leaf area index, biomass, and absorption of photosynthetically active radiation viz., NDVI, NMDI, NDWI, and NDDI (Le Houerou et al., 1988), has low to moderate correlation coefficient values.

Combined vegetation indices against rainfall and precipitation

In the variable combination (Table 4) of vegetation component (scaled vegetation index), temperature component (scaled LST), and precipitation component (scaled monthly TRMM), LST and NDI showed significant correlation with rainfall (0.26) and SPI (0.30), which indicated LST has a crucial role in modifying the NDVI such similar findings suggested by Rousta et al. (2020). This result suggests the enhanced uses of vegetation components in detecting drought for this region. The correlation between combined remote sensing indices with in-situ variables had better results than raw and scaled indices. Irrespective of the weightage, the combined NDDI (NDDI5, NDDI6, and NDDI7) displayed a positive correlation but in the raw NDDI and scaled NDDI, it was negatively correlated.

Similarly, when compared to the other combined remote sensing indices, NDDI was the least correlated variable for all the combinations. Except for NDDI of 
combined index 1 , correlation coefficient values of other composite indices with 1-month SPI is higher (Fig. $6)$, wherein most of the region was under exceptional drought $(0.0-0.1)$ to moderate drought $(0.3-0.4)$. $\mathrm{Cl}$, among the three sets of weights, performed better with SPI and rainfall during the combination with NDVI, NDWI6, and NDWI7. The results are similar to the results reported by Rhee et al. (2010) for humid regions. Among the selected indices, the correlation coefficient values reported are on par for NDVI, NDWI6, and NDWI7.

\section{Conclusion}

The study indicated no single indicator could be used as a proxy to identify agricultural drought situations. LST, a temperature component, cannot detect drought since it didn't show much correlation with rainfall $(-0.24)$ and SPI $(-0.20)$. The rainfall based component TRMM showed the highest correlation with rainfall $(0.58)$ and SPI (0.43), which provides an alternate option in the absence of in-situ meteorological variables. Independent testing of NDWI channel 6 and channel 7 can be a better alternative to NDVI for detecting. An improved scaled LST correlation with rainfall (0.19) and SPI (0.23) suggests that the inter-annual variability of ecosystem components plays a crucial role in determining vegetation covers' surface temperature. The combined indices showed an overall better correlation with rainfall and SPI, especially the combination of scaled LST and scaled TRMM, along with scaled NDVI. The scaled NDWI from band 6 of MODIS and NDWI from band 7 of MODIS also showed the best correlation possible against in-situ variables with correlation coefficient values of 0.48 (rainfall) and 0.49 (SPI).

\section{Conflict of interest}

The authors declare that they have no conflict of interest.

\section{REFERENCES}

1. Aadhar, S., \& Mishra, V. (2018). Impact of climate change on drought frequency over India. Climate Change and Water Resources in India, Publisher: Ministry of Environment, Forest and Climate Change (MoEF\&CC), Government of India.

2. Aghakouchak, A., Farahmand, A., Melton, F.S., Teixeira, J., Anderson, M.C., Wardlow, B.D., \& Hain, C.R. (2015). Reviews of geophysics remote sensing of drought: Progress, challenges. Review of Geophysics, 53, 1-29. https://doi.org/10.1002/2014RG000456

3. Ceccato, P., Flasse, S., Tarantola, S., Jacquemoud, S., \& Grégoire, J.M. (2001). Detecting vegetation leaf water content using reflectance in the optical domain. Remote Sensing of Environment, 77, 22-33. https://doi.org/1 0.1016/S0034-4257(01)00191-2

4. DOE. (2011). Season \& crop report Tamil Nadu, Depart- ment of Economics and Statistics (DOE) Chennai.

5. Di, L., Rundquist, D.C., \& Han, L. (1994). Modelling relationships between NDVI and precipitation during vegetative growth cycles. International Journal of Remote Sensing, 15, 2121-2136. https://doi.org/10.1080/0143 1169408954231

6. Farrar, T.J., \& Nicholson, S.E., Lare, A.R. (1994). The influence of soil type on the relationship between NDVI, rainfall, and soil moisture in semiarid Botswana. II. NDVI response to soil moisture. Remote Sensing of Environment, 50, 121-133. https://doi.org/10.1016/0034-4257(94) 90038-8

7. Gao, B.C. (1996). NDWI- A normalised difference water index for remote sensing of vegetation liquid from space. Remote Sensing of Environment, 58, 257-266. https:// doi.org/10.1016/S0034-4257(96)00067-3

8. Ge, Y., Cai, X., Zhu, T., \& Ringler, C. (2016). Drought frequency change: An assessment in northern India plains. Agricultural Water Management, 176, 111-121. https://doi.org/10.1016/j.agwat.2016.05.015

9. GOI (2018). Regional Report on Southwest monsoon over southern peninsular India, Government of India (GOI), I.M.D.

10. Gu, Y., Brown, J.F., Verdin, J.P., \& Wardlow, B. (2007). A five year analysis of MODIS NDVI and NDWI for grassland drought assessment over the central Great Plains of the United States. Geophysics Research Letter, 34, 1-6. https://doi.org/10.1029/2006GL029127

11. Gupta, V., Kumar Jain, M., \& Singh, V. P. (2020). Multivariate modeling of projected drought frequency and hazard over India. Journal of Hydrologic Engineering, 25(4), 04020003

12. Ji, L. \& Peters, A.J. (2003). Assessing vegetation response to drought in the northern Great Plains using vegetation and drought indices. Remote Sensing of Environment, 87, 85-98. https://doi.org/10.1016/S0034-4257(03) 00174-3

13. Kogan, F.N. (1995). Application of vegetation index and brightness temperature for drought detection. Advances in Space Research, 15, 91-100. https://doi.org/10.10 16/0273-1177(95)00079-T

14. Le Houerou, H.N., Bingham, R.L., \& Skerbek, W. (1988). Relationship between the variability of primary production and the variability of annual precipitation in world arid lands. Journal of Arid Environment, 15, 1-18. https:// doi.org/10.1016/S0140-1963(18)31001-2

15. McKee, T.B. (1995). Drought monitoring with multiple time scales, In: 9th Conference on Applied Climatology, Boston.

16. McKee, T.B., Doesken, N.J., \& Kleist, J. (1993). The relationship of drought frequency and duration to time scales, In: Proceedings of 8th Conference on Applied Climatology, Boston, p.179-183.

17. Palmer, W.C. (1965). Meteorological Drought. U.S. Department of Commerce, Weather Bureau, Washington

18. Rhee, J., Im, J., \& Carbone, G.J. (2010). Monitoring agricultural drought for arid and humid regions using multisensor remote sensing data. Remote Sensing of Environment, 114, 2875-2887. https://doi.org/10.1016/j.rse.20 10.07.005

19. Rouse, J.W., Haas, R.H., Schell, J.A., \& Deering, D.W. (1974). Monitoring vegetation systems in the Great Plains with ERTS. In: Proceedings of the Third Earth Resources 
Technology Satellite-1 Symposium, Washington: NASA, Scientific and Technical Information Office, p.309-317.

20. Rousta, I., Olafsson, H., \& Zhang, H. (2020). Impact of Drought on Vegetation Assessed by Vegetation Indices and Meteorological Factors in Afghanistan. Remote Sensing, 12(15), 2433. https://doi.org/10.3390/rs12152433

21. Wang, J., Price, K.P., \& Rich, P.M. (2001). Spatial patterns of NDVI in response to precipitation and temperature in central great plains. International Journal of Remote Sensing, 22(18), 3827-3844. https://doi.org/10.108 $0 / 01431160010007033$

22. Wang, L. \& Qu, J.J. (2007). NMDI: A normalised multiband drought index for monitoring soil and vegetation moisture with satellite remote sensing. Geophysics. Research Letter, 34(20). https://doi.org/10.1029/200 7GL031021 